\title{
Abdominal Wall Postherpetic Pseudohernia
}

\author{
Gerald Selda-Enriquez ${ }^{1}$, Ana Laura Melian-Olivera ${ }^{1}$, Patricia Burgos-Blasco ${ }^{1}$, \\ Daniel Ortega-Quijano ${ }^{1}$
}

1 Servicio de Dermatología, Hospital Universitario Ramón y Cajal, IRYCIS, Madrid, Spain

Key words: postherpetic pseudohernia, herpes zoster, infectious disease, dermatology

Citation: Selda-Enriquez G, Melian-Olivera AL, Burgos-Blasco P, Ortega-Quijano D. Abdominal wall postherpetic pseudohernia. Dermatol Pract Concept. 2021;11(1):e2020096. DOI: https://doi.org/10.5826/dpc.1101a96

Accepted: June 8, 2020; Published: December 10, 2020

Copyright: $\odot 2020$ Selda Enriquez et al. This is an open-access article distributed under the terms of the Creative Commons Attribution License BY-NC-4.0, which permits unrestricted noncommercial use, distribution, and reproduction in any medium, provided the original author and source are credited.

Funding: None.

Competing interests: The authors have no conflicts of interest to disclose.

Authorship: All authors have contributed significantly to this publication.

Corresponding author: Gerald Selda-Enriquez, MD, Servicio de Dermatología, Hospital Universitario Ramón y Cajal, Carretera Colmenar Viejo km 9.100, 28034 Madrid, Spain. Email: geraldselda@gmail.com

\section{Case Presentation}

An otherwise healthy 49-year-old man presented to the emergency department with complaint of a 3-day history of abdominal bulging (Figure 1A) in the same location of a previous herpes zoster infection. The bulge increased with Valsalva maneuver. Skin examination still revealed residual lesions of herpes zoster (Figure 1B). The final diagnosis was postherpetic pseudohernia, and at the 3-month follow-up visit, it had disappeared.

\section{Teaching Point}

Herpes zoster is characterized by clustered maculopapular and vesicular lesions along a dermatome as a result of reactivation of varicella zoster virus in the dorsal root ganglia of

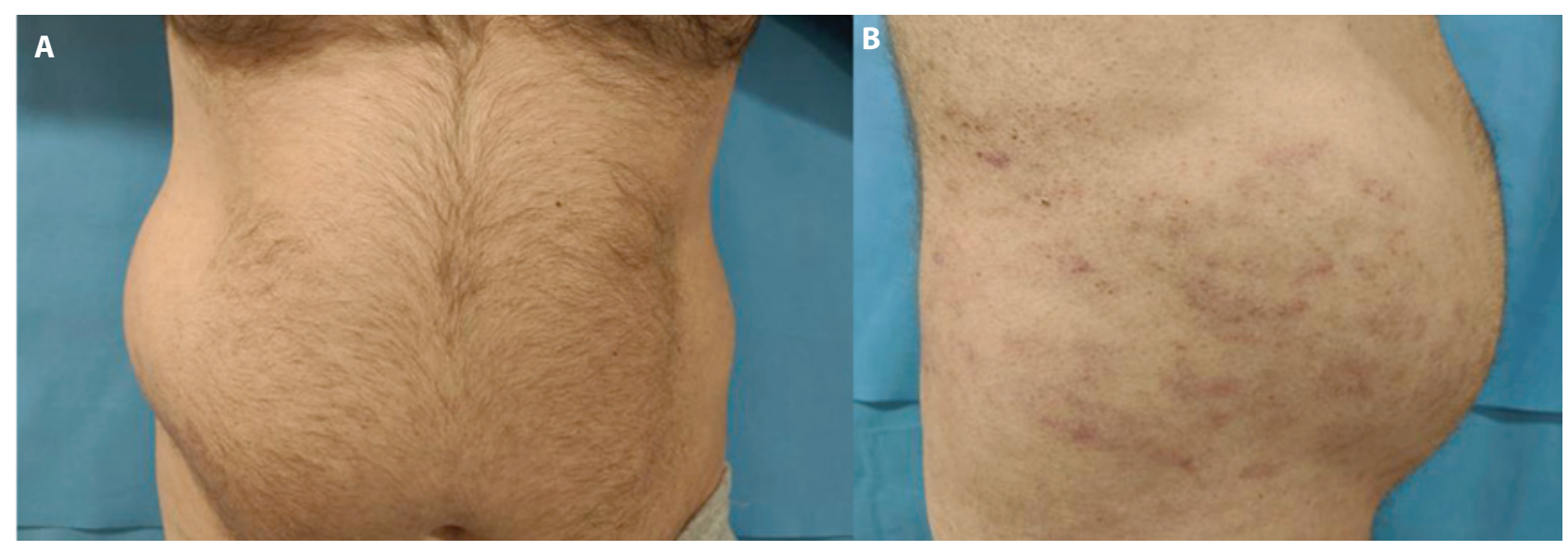

Figure 1. (A) Bulging is seen in the right abdomen. (B) Erythematous maculopapular lesions due to herpes zoster are observed along the right T9-10 dermatome, consistent with the area where bulging is seen. 
peripheral nerves. An infrequent complication is postherpetic pseudohernia which arises when the anterior root ganglia is involved, thus provoking muscular paralysis [1]. Differential diagnosis with true hernia by means of clinical and radiological exams is critical, as it does not require surgery and tends to disappear spontaneously in the majority of cases after less than a year [2].

\section{References}

1. Healy C, McGreal G, Lenehan B, McDermott EW, Murphy JJ. Self-limiting abdominal wall herniation and constipation following herpes zoster infection. QJM. 1998;91(11):788 789. DOI: 10.1093/qjmed/91.11.788. PMID: 10024942.

2. Yoo J, Koo T, Park E, et al. Abdominal pseudohernia caused by herpes zoster: 3 case reports and a review of the literature. JAAD Case Rep. 2019;5(8):729-732. DOI: 10.1016/j.jdcr.2019.06.019. PMID: 31440570. 